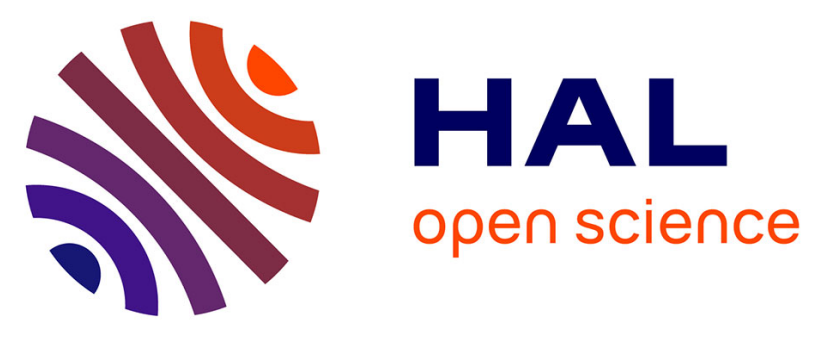

\title{
Variants in the non-coding region of the TLR2 gene associated with infectious subphenotypes in pediatric sickle cell anemia
}

Susana David, Pedro A. Aguiar, Liliana Antunes, Alexandra Dias, Anabela

Morais, Anavaj Sakuntabhai, João Lavinha

\section{To cite this version:}

Susana David, Pedro A. Aguiar, Liliana Antunes, Alexandra Dias, Anabela Morais, et al.. Variants in the non-coding region of the TLR2 gene associated with infectious subphenotypes in pediatric sickle cell anemia. Immunogenetics, 2018, 70 (1), pp.37-51. 10.1007/s00251-017-1013-7 . pasteur-02003876

\section{HAL Id: pasteur-02003876 \\ https://hal-pasteur.archives-ouvertes.fr/pasteur-02003876}

Submitted on 19 Apr 2019

HAL is a multi-disciplinary open access archive for the deposit and dissemination of scientific research documents, whether they are published or not. The documents may come from teaching and research institutions in France or abroad, or from public or private research centers.
L'archive ouverte pluridisciplinaire HAL, est destinée au dépôt et à la diffusion de documents scientifiques de niveau recherche, publiés ou non, émanant des établissements d'enseignement et de recherche français ou étrangers, des laboratoires publics ou privés.

\section{(1)(1) $\$(0)$}

Distributed under a Creative Commons Attribution - NonCommercial - ShareAlikel 4.0 
2 Variants in the non-coding region of the TLR2gene associated with

3 infectious subphenotypes in pediatric sickle cell anemia

5 Susana David $^{1,2^{*}}$, Pedro Aguiar $^{3}$, Liliana Antunes ${ }^{4}$, Alexandra Dias $^{5}$, Anabela Morais ${ }^{6}$,

6 AnavajSakuntabhai ${ }^{7,8}$, João Lavinha ${ }^{1,9}$

$8{ }^{1}$ Departamento de Genética Humana, Instituto Nacional de Saúde Doutor Ricardo Jorge,

9 Lisboa, Portugal

$10{ }^{2}$ Centro de Estudos de Ciência Animal, Instituto de Ciências e Tecnologias Agrárias e

11 Agro-Alimentares, Universidade do Porto, Porto, Portugal

$12{ }^{3}$ Centro de Investigação em Saúde Pública, Escola Nacional de Saúde Publica,

13 Universidade Nova de Lisboa, Lisboa, Portugal

$14{ }^{4}$ Departamento de Epidemiologia, Instituto Nacional de Saúde Doutor Ricardo Jorge,

15 Lisboa, Portugal

$16{ }^{5}$ Departamento de Pediatria, Hospital Prof Doutor Fernando Fonseca, Amadora, Portugal

$17{ }^{6}$ Departamento de Pediatria, Hospital de Santa Maria, Lisboa, Portugal

$18{ }^{7}$ Unité de la Génétique Fonctionnelle des Maladies Infectieuses, Institut, Pasteur, Paris,

19 France

$20{ }^{8}$ Centre National de la Recherche Scientifique, URA3012 Paris, France 
$21{ }^{9}$ BiolSI, Faculdade de Ciências, Universidade de Lisboa, Lisboa, Portugal

24 Key words: Sickle cell anemia; TLR2; genetic variants; viral and bacterial infection;

25 hemolytic component; genotype-to-phenotype association

27 Running title: TLR2 and infection in pediatric sickle cell anemia

* Corresponding author. Address: Departamento de Genética Humana, Instituto Nacional

30 de Saúde Doutor Ricardo Jorge, Av. Padre Cruz, 1649-016, Lisboa, Portugal. Tel.: (+351)

31217519200 , fax: (+351) 217526400 .

32 E-mail address: suzana.david@insa.min-saude.pt 
Sickle cell anemia (SCA) is characterized by chronic hemolysis, severe vasoocclusive crises (VOC) and recurrent often severe infections. A cohort of 95 SCA pediatric patients was the background for genotype-to-phenotype association of the patient's infectious disease phenotype and three noncoding polymorphic regions of the TLR2 gene, the -196 to -174 indel, SNP rs4696480 and a (GT)n short tandem repeat. The infectious subphenotypes included: $(A)$ recurrent respiratory infections, and $(B)$ severe bacterial infection at least once during the patient's follow-up. The absence of the haplotype [Del]-T$[n \geq 17]($ Hap7) in homozygocity protected against subphenotype (B), in a statistically significant association, resisting correction for multiple testing. For the individual loci, the association between the SNP rs4696480 T allele and subphenotype (A), whereas the A/A genotype was protective, and a deleterious effect of the A/T genotype with subphenotype (B), as well as including the protective effect of -196 to -174 insert (Ins) and deleterious effect of the deletion (Del) in homozygocity, against subphenotype (B). Moreover, a reduction in the incidence rate of severe bacterial infection was associated to a rise in the hemolytic score, fetal hemoglobin levels (prior to hydroxyureia treatment) and 3.7-kb alphathalassemia. Interestingly, differences between the effects of the two latter covariables favoring a reduction in the incidence rate of subphenotype $(B)$ contrast with a resulting increase in relation to subphenotype $(A)$. These results could have practical implications in health care strategies to lower the morbidity and mortality of SCA patients. 


\section{Introduction}

As the first line of host defense, the innate immune system discriminates between varieties of pathogens inter alia via the pattern-recognition receptors (PRRs). These receptors recognize as ligands essential microbial components, known as pathogenassociated molecular patterns (PAMPs), horizontally expressed either across all the major classes of infectious agents or more specifically in a particular class. Different PRRs react with specific PAMPs, leading to distinct immunological responses in the early phase of infection (Akira et al., 2006).

Toll-like receptors (TLRs) are a pluripotent family of PRRs recognizing PAMPs from a large spectrum of infectious agents. In humans, the TLR family of transmembrane proteins comprises 10 functional members (Takeda et al., 2003). Amongst these, TLR2 has been associated with the innate immune response against bacteria, fungi, parasites and viruses through the recognition of a variety of specific lipids of the cell envelopes and some viralenvelope proteins (Kawai and Akira, 2005; Misch and Hawn, 2008; Thompson and Iwasaki 2008). Moreover, TLR2 dimer formation with TLR1 and TLR6 and interaction with non-TLR receptors further diversifies its recognition potential (Kawai and Akira, 2011).

Genetic variation in the human TLR2 gene (located on chromosome 4q32), can influence the host susceptibility to infection (O'Neill et al., 2009; Lin et al., 2012; de Oliviera Nascimento et al., 2012; Medvedev, 2013) including by bacterial agents (Ma et al., 2007; Hawn et al., 2009; Chen et al., 2010; Alter et al., 2011; Casanova et al., 2011; Nischalke et al., 2011; Song et al., 2011; Esposito et al., 2014; Zhang et al., 2013) and enveloped viruses (Cai and Zheng, 2012; Nischalke et al., 2012; Novis et al., 2013; Bagheri et al., 2014; Triantafilou et al., 2014; Ma et al., 2014; Reuven et al., 2014; Chen et al., 2015; Hernandez et al., 2015). Moreover, genetic polymorphic variants heterogeneously 
distributed between populations of different ethnic or geographical background have been described in association with inter-population susceptibility differences (loana et al., 2012; Mukherjee et al., 2014).

The genetic variants in human $T L R 2$ reported in the literature as being related with susceptibility to infection include:

(i) The-196 to -174 insertion or deletion (indel) of 22 bp localized in the TLR2 first untranslated exon, associated with susceptibility to infections of various etiologies(Nischalke et al., 2011, 2012; Velez et al., 2010; Greene et al., 2012).

(ii) The single nucleotide polymorphism (SNP) rs4696480, c.-16934A>T (g.153685974T>A), localized in the TLR2promoter, in a preliminary study associated to susceptibility to pulmonary bacterial infections in sickle cell disease (Rostane et al., 2012).

(iii) The microsatellite, short tandem repeat (STR),(GT)n polymorphism in the TLR2intron $2(12 \leq \mathrm{n} \leq 28)$, described as highly variable between populations (Yim et al., 2004) and associated with different susceptibilities to tuberculosis in distinct populations (Yim et al., 2006), as well as being implicated in other infections(Folwaczny et al., 2011).

Sickle cell anemia (SCA) is a life threatening clinically heterogeneous monogenic autosomal recessive chronic anemia (Driss et al., 2009). The disease is characterized by recurrent episodes of severe vasoocclusion, chronic hemolysis and recurrent often severe infection. It is caused by the homozygosity for a single nucleotide substitution in the human beta-globin gene (HBB) (located on chromosome 11p15.5). This mutation (HBB:c.20A>T) gives rise to a hemoglobin structural variant $(\mathrm{HbS})$, that under low oxygen partial pressure 
polymerizes, leading to red blood cell sickling and a clinically heterogeneous pathophysiological cascade.

Development and validation of early predictors of disease severity is a strategy oriented towards lowering morbidity and mortality in the affected patients. In this context, it has been our purpose to investigate the association of the above mentioned noncoding genetic variation in TLR2 on the infection phenotype of SCA pediatric patients.

\section{Methods}

\section{Study population}

112 Ninety-five unrelated patients with SCA were recruited on the basis of the criterion of having 113 more than three and under 20 years. This 95 patient subgroup was part of a total of 99 SCA 114 patients, attending the pediatric wards of two general hospitals in Greater Lisbon, enrolled 115 in a previous longitudinal study with a total follow-up of 557 person*years (Coelho et al., 116 2014). Patient information relative to gender, alpha-thalassemia, $H B B^{\star} S$ haplotypes and 117 fetal hemoglobin level was available from this study, and as previously described, Sub118 Saharan African ancestry accounted for the majority of the subjects (97\%). The study 119 procedures were approved by INSA's ethics committee and are in accordance with the 120 Helsinki Declaration of 1975. Written informed consent, was given by the patients' legal 121 representatives. 
124 Three TLR2 variants having been associated with infection susceptibility were selected for genotyping. These included the -196 to -174 a 22 bp nucleotide indel in the first untranslated exon, promoter SNP rs4696480, c.-16934A >T (g.153685974T>A), and the (GT)n STR polymorphism in the second intron. Genotyping of these loci was performed for all 95 patients.

All PCR reactions were carried out in a total reaction volume of $25 \mu \mathrm{L}$, containing $22,5 \mu \mathrm{L}$ in house PCR Buffer (Table S1); $0.25 \mu \mathrm{L}$ of each primer (working solution $25 \mu \mathrm{M}$ ); 0,1 $\mu \mathrm{L}$ Taq

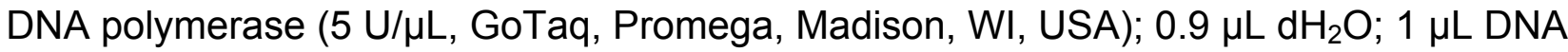
(100 ng/ $\mu \mathrm{L})$.

The genotyping of the TLR2 c.-196 to -174 indel was carried out using the forward 5'CACGGAGGCAGCGAGAAA-3' and reverse 5'-CTGGGCCGTGCAAAGAAG-3' primers (Tahara et al., 2007). The PCR program consisted in an initial denaturation step at $95^{\circ} \mathrm{C}$ for $5 \mathrm{~min}, 35$ cycles of $95^{\circ} \mathrm{C}$ for $30 \mathrm{~s}, 60^{\circ} \mathrm{C}$ for $40 \mathrm{~s}$, and $72^{\circ} \mathrm{C}$ for $40 \mathrm{~s}$, and a final extension step at $72{ }^{\circ} \mathrm{C}$ for $7 \mathrm{~min}$. The PCR products were visualized on a $4 \%$ agarose gel stained with ethidium bromide and interpreted as follows: wild type, a single 286 bp band (Insertion/Insertion, Ins/Ins); homozygous for the deletion, one 264 bp band (Deletion/Deletion, Del/Del); heterozygous, two bands of 286 bp (Ins) and 264 bp (Del).

The genotyping of the rs4696480 SNP was carried out using restriction fragment length polymorphism (RFLP) analysis. Digestion with the restriction enzyme Hphl (NEB® New and reverse 5'-TGTTATCACCAAGGGAGCAG-3' primers were used. The PCR program consisted in an initial denaturation step at $95^{\circ} \mathrm{C}$ for $5 \mathrm{~min}, 30$ cycles of $95^{\circ} \mathrm{C}$ for $30 \mathrm{~s}, 60^{\circ} \mathrm{C}$ 
restriction of the PCR products was carried out at $37^{\circ} \mathrm{C}$ for 3 hours. The digested products were visualized on a $2 \%$ agarose gel stained with ethidium bromide and interpreted as follows: homozygous T/T three bands of $212 \mathrm{bp}, 68 \mathrm{bp}$ and $47 \mathrm{pb}$; heterozygous T/A four bands of $260 \mathrm{bp}, 212 \mathrm{bp}, 47 \mathrm{bp}, 68 \mathrm{pb}$; homozygous A/A two bands of $260 \mathrm{bp}$ and $68 \mathrm{pb}$.

For genotyping of the STR polymorphism, the surrounding region in intron 2 was amplified using the FAM (fluorescein marker 6-carboxyfluorescein) labeled forward primer 5'-FAMGCATTGCTGAATGTATCAGGGA-3', and the reverse primer 5'-

CTTGAGAAATGTTTTCTAGGC-3' (Folwaczny et al., 2011). The PCR program consisted in an initial denaturation step at $95^{\circ} \mathrm{C}$ for $5 \mathrm{~min}, 35$ cycles of $95^{\circ} \mathrm{C}$ for $30 \mathrm{~s}, 56{ }^{\circ} \mathrm{C}$ for $30 \mathrm{~s}$, and $72{ }^{\circ} \mathrm{C}$ for $30 \mathrm{~s}$, and a final extension step at $72{ }^{\circ} \mathrm{C}$ for $10 \mathrm{~min}$. The number of (GT)n repeats was identified by sizing the PCR products with the $A B I 310$ sequencer and the Genescan Analysis 2.1 software (Applied Biosystems, Foster City, CA, USA). The following subdivision based on the number of repeats $(n)$ was used: Allele $S, n \leq 16$; Allele $M, 17 \leq n$ $\leq 22$, and Allele $L, n \geq 23$, which was further simplified as a binary variable $S$ versus others (M or L) (Yim et al., 2006).

Hardy Weinberg equilibrium was verified using the standard asymptotic (1 df genotypic chisquared test) in all instances. For the STR the Hardy-Weinberg Equilibrium was verified considering the $S$ allele relative to the others $(\mathrm{M}$ or $\mathrm{L})$.

Haplotype reconstruction from the genotyping data was carried out using the PHASE, version 2.1, program (Stephens et al., 2001, 2003) and is summarized in Table 1. The distances between the variants (relative to the arbitrary position c.-18619, 5' - indel (untranslated exon 1) - SNP (promoter) - microsatellite (exon 2) - 3': 66/1685/18475 bp respectively), and the binary subdivision of the TLR2 (GT)n locus allowed for their approximation as single loci by the PHASE program. 
173 Derivation of a hemolytic component

174 The derivation of a hemolytic component followed the strategy described by Nouraie and

175 collaborators (2013). These authors derived a hemolytic component using principal 176 component analysis (PCA) with 4 degrees of freedom from data on the reticulocyte count

$177(\%)$, and serum lactate dehydrogenase (U/L), aspartate aminotransferase (U/L) and total 178 bilirubin concentrations ( $\mathrm{mg} / \mathrm{dL})$. Levels of aspartate aminotransferase were not available in 179 our patient database, but as this is a more distal marker of hemolysis and the other three 180 are more direct markers, we worked with these remaining three degrees of freedom. For 181 the PCA only steady state values were used. The association of this component with 182 clinical phenotypes was assessed.

Genotype-to-phenotype association studies

A stepwise approach in the statistical analysis of genotype-to-phenotype association was used (Fig. S1). In this manner the open-source whole genome association analysis toolset PLINK v1.07 program (Purcell et al., 2007), particularly adapted to cross-sectional association analysis of SNPs, was applied to the analysis of SNP rs4696480, c.-16934A>T, in exploratory preliminary association testing for the selection between various possible infectious disease subphenotypes. This preliminary analysis was followed by other crosssectional analytical methods, for association testing of the variants and haplotypes of the all the different TLR2 polymorphic loci under consideration (indel, SNP and STR). These informative tests included descriptive statistics for the comparison of rates or the chi-square test applied dichotomous traits. Lastly, a quasipoisson regression model was applied in the 
association studies between the different $T L R 2$ polymorphic loci and the selected quantitative or rare event (dichotomous) disease subphenotypes. This allowed for analysis of the time based cohort and the prediction of correlated dependent variables.

For analysis using the PLINK program, genotype-to-phenotype association was carried out redefining the infectious status as a binary trait, considering the number of infections/ time at risk in person*years and "time at risk" equal to the time under observation during the follow-up. A positive relationship was obtained when "the average rates of the phenotype per patient (number of infections/ time at risk)/ the average rates of the phenotype for all the patients (number of infections/ time at risk) $(n=95) ">1$. The allelic, recessive and dominant inheritance models were tested and the Cochran-Armitage trend test performed. No correction for multiple comparisons was conducted at this level of analysis.

For descriptive statistics, the binary variables were expressed as proportions and the continuous variables as means \pm standard deviation. For the comparison of means, the two-sample t-test was used.

Descriptive statistics was carried out on the phenotypes showing a statistically significant result in the preliminary PLINK analysis. For the quantitative infectious phenotype variables, we compared the average rates of the phenotype for all the patients (number of infections/ time at risk), in the presence and in the absence of the TLR2variants or their haplotypes. If the presence of the genotype was associated with an increase in the incidence of respiratory infections (positive statistical effect), this indicated a deleterious genotype with a potentially unfavorable clinical effect. On the contrary, if the presence of the variant was associated with a decrease in the incidence of respiratory infections (negative statistical effect), this indicated a protective genotype with a potentially favorable clinical effect. For the dichotomous infectious phenotype variables (presence vs. absence), the differences in 
allele frequencies and genotype distributions between the 2 groups was evaluated using the Fisher's exact test (two sided) and the odds ratio (OR) was calculated under different genetic models to measure the risk of infection.

The inheritance models for the TLR2 variants and their haplotypes were tested using a generalized linear model assuming a quasipoisson regression model for the SCD patients

224 (n = 95): Phenotype $\sim$ Genotype + steady state hemoglobin level + steady state leukocyte count + fetal hemoglobin (prior to hydroxyurea treatment) + haemolytic component + alphathalassemia. The allelic and genotypic inheritance models were tested for each variant. This statistical analysis was carried out in R (Team, R.C., 2013). The quasipoisson regression model adjusts for possible deviations from the poisson assumptions (Ver Hoef and Boveng, 2007). Risk estimates were obtained using incidence rate ratio calculations for those inheritance models showing statistically significant associations to infection after forward optimization.

232 The haplotypes defined by the three TLR2 loci were analyzed for association by 233 considering each haplotype as an allele.

234 Genotype-to-phenotype associations were considered statistically significant when the $p \leq$ 0.05. However, to control type I errors, the Bonferroni correction for multiple comparisons (Bland and Altman 1995), was performed for the genetic models tested. For subphenotype (A) the adjusted alpha was 0.001667 , for a number of tests performed per allele $n=30$ (six covariables for two inheritance models, allelic and genotypic, with 2 tests for the allelic and 3 for the genotypic) and for subphenotype (B) the adjusted alpha was 0.001471 , for $n=34$ 240 (adding to the above four Fisher's exact tests). 


\section{Results}

\section{Study population}

245 In this study, genetic association studies for various infectious disease phenotypes were 246 performed for 95pediatric SCA patients(mostly of Sub-Saharan origin) and infectious 247 episodes occurring within an age range of over three and under 20 years (Fig. 1). The total 248 observation period for the cohort (longitudinal study) was 433.4 person*year. The 249 distribution of the observations per age group is represented in Fig.1 and the average age 250 at observation was $7.7 \pm 3.7$ years. The mean follow-up per patient was $4.6 \pm 1.5$ years. The 251 male/ female (M/F) sex ratio was 1.21.Values for the other population data included: the 252 average steady state levels of hemoglobin $7.9 \pm 0.8(\mathrm{~g} / \mathrm{dL})$, fetal hemoglobin levels prior to 253 eventual hydroxyurea treatment $11.0 \pm 7.6(\%)$ and alpha-thalassemia $(-\alpha 3.7-k b$ deletion 254 alleles) $43.6 \%$ (41/94) (data unavailable for one patient). The major $H B B^{*} S$ haplotype allele was Bantu (Bantu 127; Benin 32; Senegal 26; other 4), and the major genotype Bantu/Bantu (Bantu/Bantu $(n=54)$, Bantu/[Other than Bantu] $(n=19)$ and [Other than Bantu]/[Other than Bantu] $(\mathrm{n}=22))$.

258 Phenotypic characterization of the infection status during follow-up, was determined by 259 standard procedures and collected from the patients' hospital records. The $10^{\text {th }}$ revision of 260 the International Statistical Classification of Diseases and Related Health Problems (ICD10)

261 http://apps.who.int/classifications/icd10/browse/2016/en, was used to classify infectious episodes. The latter were observed within vasoocclusive crisis (VOC) and between crises (steady-state) (IC) (Fig.2 to 3). The majority of the patients, 76\% (72/95), were regularly under prophylactic antibiotic treatment and virtually all of them completed an extended 
vaccination program. In a total of 1351observations (484 during crisis and 867in steadystate), 527 infectious episodes, 722observations without infection and 102 observations without reference to infection were reported (Fig.2). Reference to the etiologic agent of infection was limited to the clinically more severe episodes. From the available clinical data however, viral infections appeared characteristic of the inter-crisis period whereas during vassoclusive crisis (VOC) the distribution between infections caused by viruses and those by bacteria was more equitable. Moreover, a viral etiology also appeared characteristic of the respiratory infections (Fig. 3).

Hemolytic component

A hemolytic component derived by principal component analysis (PCA) with 3 degrees of freedom from steady-state serum lactate dehydrogenase and total bilirubin, and peripheral blood reticulocyte count in the 95 SCA patients had a mean of $0(S D=1.23)$ and predicted $51 \%$ of the variation among all three variables (Eigenvalue=1.51). These results are comparable to those obtained by Nouraie and collaborators (2013)using a PCA with 4 degrees of freedom in 415 SCA patients, predicting $55 \%$ of the variation among all four variables (Eigenvalue $=2.20)$, having a mean of $0(S D=1.50)$.

The mean hemolytic component value was significantly lower with the alpha-thalassemia genotype $(p=0.023)$ as has been previously reported by Nouraie and collaborators (2013). However, we neither observed a significant association with gender $(p=0.922)$, with a mainly pre puberty aged population, nor a positive correlation with increasing percentage of fetal hemoglobin, prior to hydroxyurea treatment, or hydroxyurea treatment (Fig. S2A). This may possibly be due to the fact that we did not study the fetal hemoglobin levels posterior to hydroxyurea treatment but used the administration of hydroxyurea, in $18 \%(17 / 95)$ of the 
patients as a gross, approximation for higher fetal hemoglobin levels. However, a significant negative correlation with increasing percentage of steady state hemoglobin was observed $(p=0.001)($ Fig. S2B $)$.

TLR2 genotype and haplotype analysis

Allele frequencies in the study population, included, for the -196 to -174 indel, 0.268 $(51 / 190)$ and $0.732(139 / 190)$ for the Del and Ins alleles, respectively, for the SNP rs4696480, c.-16934A>T $0.426(81 / 190)$ and $0.574(109 / 190)$ for the A and T alleles, respectively, and for the (GT)n STR polymorphism 0,121 (23/190) and 0.879 (167/190) for 298 the S and Other (M or L) alleles respectively. characteristic also shared by Hap7.

Genotype-to-phenotype association studies

\section{Data analysis strategy}

Genotype-to-phenotype association studies followed a data analysis strategy (Fig. S1). The stepwise approach included an extensive exploratory method used for subphenotype selection based on SNP analysis using the Open-source whole genome association v1.07 program (Purcell et al., 2007), followed by exploratory methods to detect statistical tendencies based on descriptive statistics, in the analysis of means of proportions, or the 
311 Fisher's exact test, in the analysis of dichotomous traits. Finally, a longitudinal analysis of

312 dichotomous and quantitative traits using a quasipoisson regression model offered higher

313 statistical power and allowed the prediction of correlated dependent variables.

314 Phenotype selection

315 Six subphenotypes of the patients' infectious status, were originally defined for statistical testing: (A) "number of respiratory infections during the patient's follow-up"; (B) "severe bacterial infections at least once during the patient's follow-up"; (C) "number of all infectious episodes during the patient's follow-up"; (D) "number of infectious episodes without hospitalization during the patient's follow-up"; (E) "number of infectious episodes with hospitalization during the patient's follow-up"; (F) "number of infections other than respiratory during the patient's follow-up". The number of infections per time at risk was measured in person*years considering the "time at risk" equal to the time under observation during the follow-up. The phenotypic group (B) was the only originally constructed as a binary trait. The following bacterial infections, affecting a total of nine patients in spite of antibiotic prophylaxis, were observed for the phenotypic group (B): Buruli ulcer and salmonellosis (observed in the same patient), pneumococcal meningitis, pyodermitis, bacteremia and osteomyelitis.

328 Preliminary subphenotype selection was carried out using the PLINK v1.07 program for genotype to phenotype association analysis of the TLR2SNP rs4696480, c.-16934A>T. The allelic, recessive and dominant inheritance models were tested and the Cochran-Armitage trend test performed (Table 2). Statistically significant results (without corrections for 332 multiple comparisons) were only obtained for the SNP's association with the subphenotype 333 (A)“number of respiratory infections during the patient's follow-up”. 

patient's follow-up"

Descriptive statistics, carried out on the single infectious subphenotype, showed a statistically significant result in the preliminary analysis, i.e. subphenotype (A) "number of respiratory infections during the patient's follow-up" (Table S2). For this we compared the average rates of respiratory infections for all the patients (number of respiratory infections/ time at risk), in the presence and in the absence of the TLR2 variants or their haplotypes. If the presence of the genotype was associated with an increase in the incidence of respiratory infections (positive statistical effect), this indicated a deleterious genotype with a potentially unfavorable clinical effect. The descriptive statistics suggested a number of deleterious tendencies, including for SNP rs4696480, c.-16934, T allele and the -196 to 174 Del allele.

The association, of the subphenotype (A) "number of respiratory infections during the patient's follow-up" with the TLR2 variants and their haplotypes, was then statistically tested using a quasipoisson regression model. No statistically significant results were detected with the univariable model, Phenotype $\sim$ Genotype. With the multivariable model (see methods), statistical confirmation of the suggestive results from the descriptive statistics was obtained only for TLR2 SNP rs4696480, c.-16934A>T (Table3). Risk estimates obtained as a result of the allelic test showed that, in relation to the reference group (allele A), the presence of allele T caused a deleterious effect resulting in an increase of the incidence rate ratio $(p=0.00903)$. A protective effect of allele A was observed in homozygosity ( $p=0.01328$ ). For allele T (allelic model) and allele A in homozygosity (genotypic model) the deleterious effects of the covariables 3.7-kb alpha-thalassemia and fetal hemoglobin levels (prior to hydroxyurea treatment) were also observed, whereas the 
steady state hemoglobin level was protective. The Bonferroni correction for multiple comparisons of these results however did not confirm the statistical significance of the increase of the incidence rate ratio in the number of respiratory infections in the presence of allele T (adjusted $\alpha=0.001667$ ).

Using the quasipoisson regression analyses, no statistically significant associations were obtained for this phenotype in relation to haplotypes.

Statistical analysis of subphenotype (B) "severe bacterial infections at least once during the patient's follow-up"

Although the PLINK analysis did not reveal a statistically significant association of the SNP rs4696480, c.-16934A>T, with the subphenotype (B), "severe bacterial infections at least once during the patient's follow-up", we considered it relevant to perform the Fisher's exact test and quasipoisson regression model on the TLR2 variants and their haplotypes for this rare phenotype (frequency < 0.10$)($ Tables4 to 7 ), since this SNP has been reported associated with severe bacterial infections (Rostane et al., 2012).

For the individualTLR2 variants, no statistically significant results were detected with the quasipoisson regression univariable model, Phenotype $\sim$ Genotype. With the multivariable model (see methods), statistically significant results were obtained for the SNP rs4696480, C. $-16934 \mathrm{~A}>\mathrm{T}$ (Table 4), and the -196 to -174 indel (Table 5). A deleterious effect of the A/T genotype $(p=0.00311)$ was observed along with that of the covariable steady state leukocyte count, whereas the covariables hemolytic component and fetal hemoglobin levels (prior to hydroxyurea treatment) were protective. A protective effect for the -196 to -174 Ins allele $(p=0.0308)$ and a deleterious effect of the Del/Del $(p=0.0381)$ genotype was also observed, along with the protective effects of the covariables hemolytic component and 
381 fetal hemoglobin levels (prior to hydroxyurea treatment). These results however did not resist the Bonferroni correction for multiple comparisons (adjusted $\alpha=0.001471$ ).

Considering haplotype analysis, the Fisher's exact test revealed a deleterious effect of Hap7 (OR = 24.29; 95\%Cl 1.95-302.20; $p=0.023)($ Table S3). However, the result did not resist the correction for multiple comparisons. Moreover, the risk estimates obtained assuming a univariable quasipoisson regression model (Phenotype $\sim$ Genotype) $(p=$ 0.0060 ) did not resist the Bonferroni correction (adjusted $\alpha=0.001471$ ). However, the risk estimates obtained using the multivariable model (see methods) (Table 6) resisted the Bonferroni correction for multiple comparisons. Results showed that, in relation to the reference group [Other than Hap7], the presence of Hap7 in the allelic model caused an increase of the incidence rate ratio $(p=0.00145)$. On the contrary, in relation to Hap7/[Other than Hap7] (no individuals presented the Hap7/Hap7 genotype), the absence of Hap7 in the homozygous genotype [Other than Hap7]/[Other than Hap7]caused a reduction of the incidence rate ratio $(p=0.00145)$.

With the quasipoisson regression model, a statistically significant association independent of genotype was also obtained for the phenotype (B), "severe bacterial infections at least once during the patient's follow-up", relative to the hemolytic component (Table 7).An hemoglobin levels (prior to hydroxyurea treatment) and 3.7-kb alpha-thalassemia. increase in one hemolytic component unit caused a decrease of $82 \%$ in the incidence rate ratio $(p=0.000366)$. This result was positively influenced by the covariables fetal

\section{Discussion}


404 The clinical course of SCA is an alternation of periods of steady state and painful VOCs.

405 VOCs ultimately result from the reduced solubility of deoxygenated $\mathrm{HbS}$, its subsequent polymerization and the formation of the characteristic sickled red blood cells resulting in life threatening pathophysiological changes (Kaul et al., 1996). These changes contribute toa predisposition to infections, which constitute the major cause of morbidity and mortality in these patients. Moreover, infective factors may in themselves trigger VOCs (Ahmed, 2011). In developed countries, particular care is taken to reduce the infectious episodes through extensive immunization and the use of prophylactic or therapeutic antimicrobial agents. The pediatric patients in our cohort were under close and regular medical supervision and subject to comprehensive preventive or curative measures. Nevertheless, severe and recurrent infectious episodes were reported.

Both environmental and genetic factors appear to accrete in the determination of sickle cell disease phenotypes (Driss et al., 2009). Genotype-phenotype association studies have been conducted to identify genetic modulators of SCA phenotypes (Steinberg, 2008; Steinberg and Sebastiani 2012), helping to understand the environmental and physiological interactions at play in the onset, course and outcome of the disease.

The role of TLRs against invading organisms has been the subject of several literature reviews (O'Neill et al., 2009; Lin et al., 2012; de Oliviera Nascimento et al., 2012; Medvedev, 2013). These type I transmembrane glycoproteins belong to the so-called pattern recognition receptors (PRRs) of the innate immune system. They are expressed by macrophages, neutrophils, dendritic cells (DCs), natural killer (NK) cells, and epithelial and endothelial cells (Kawai and Akira, 2011; Hippenstiel et al., 2006) and recognize evolutionarily conserved molecular structures essential to pathogen survival. Amongst the ten members of the human TLR family, TLR2 is a particularly pluripotent receptor due to 
428 dimer formation with TLR1 and TLR6 in addition to interaction with non-TLR receptors 429 (Kawai and Akira, 2005). It is therefore not surprising that susceptibility to infections of 430 diverse etiologies has been associated toTLR2and its genetic variants.

431 In this work, a longitudinal study on a cohort of 95 SCA pediatric patients, was the 432 background for analyzing the genetic association of six infectious subphenotypes and three 433 loci in the noncoding regions of the TLR2 gene, namely the -196 to $-174,22$ bp deletion in 434 the first untranslated exon, the promoter SNP rs4696480, c.-16934A $>$ T (g.153685974T>A), 435 and the (GT)n STR polymorphism in the second intron.

A stepwise approach to the genotype-to-phenotype association statistical analysis allowed firstly, in preliminary analysis of the TLR2 SNP c.-16934A>T variants, the identification of a relevant infectious subphenotype. This was followed by the observation of deleterious or protective tendencies of the SNP, indel and STR variants and their haplotypes in cross sectional analyses relative to the selected subphenotype. Finally, the use of a quasipoisson regression model optimized the statistical analysis through the incorporation of covariable 442 effects.

In the preliminary genotype-to-phenotype association analysis using the PLINK program a potential association of the average rates per patient of the subphenotype "number of respiratory infections during the patient's follow-up"with TLR2SNP c.-16934A>T was identified. This analysis was followed by descriptive statistics on this subphenotype, comparing the average rates of respiratory infections for all the patients (number of respiratory infections/ time at risk in person*year) with the variants and their haplotypes. The trends observed in the preliminary and descriptive analyses were statistically confirmed 450 in a quasipoisson regression model for the locus variants. The deleterious effect of the T 
451 allele as opposed to a protective effect of the A/A genotype in relation to respiratory 452 infections was thus statistically confirmed.

In our cohort, virus infections appear to be more frequent than bacterial in the episodes of respiratory infections. In an extensive review Wu and Chu (2009) document on how the host's capability to recognize microbes can influence susceptibility to asthma. Certain viral infections including those affecting the respiratory tract, such as RSV are strongly associated with asthma prevalence in children. Moreover, as reviewed by Klaassen and collaborators (2013), the minor allele T of TLR2c.-16934A $>$ T was related to childhood asthma and current asthma symptoms in 3 out of 5 studies (Eder et al., 2004; Kormann et al., 2008; Bottema et al., 2010; Kerkhof et al., 2010; Miedema et al., 2012). Therefore, our results concerning the possible implication of this variant in the susceptibility to infections of reports.

The analysis of the occurrence of at least one severe bacterial infection during the patient's follow-up, was also tested relative to TLR2 SNP c.-16934A $>$ T, prompted by a previous study showing that the homozygous genotypes $A / A$ and $T / T$ were associated with severe bacterial infections in sickle cell patients whereas the heterozygous $A / T$ genotype was more frequent in patients without infections $(p<0.001)$ (Rostane et al., 2012). However, contrary to the reported results (Rostane et al., 2012), we observed a deleterious effect of the heterozygous $A / T$ genotype in patients with severe bacterial infections.

471 The descriptive analyses in relation to the number of respiratory infections suggested a 472 deleterious effect of the -196 to -174 Del/Del homozygote. Using the quasipoisson regression model, this was not statistically confirmed for respiratory infections. As concerns 474 the subphenotype of a severe bacterial infection at least once during the patient's follow-up, 
475 the quasipoisson regression revealed the tendencies for a protective effect of the Ins allele 476 and a deleterious effect of the Del/Del genotype. The Del allele has been implicated in the

477 occurrence of infections of various etiologies (Nischalke et al., 2011, 2012; Velez et al., 2010; Greene et al., 2012; Hishida et al., 2010; Zeng et al., 2011). Functionally, the -196 to -174 Del/Del genotype has been reported to show decreased transcriptional activity of the TLR2 gene (Nischalke et al., 2012; Noguchi et al., 2004).

Concerning the (GT)n STR polymorphism in the TLR2 intron 2, the three major TLR2 haplotypes with frequencies $\geq 5 \%$ (Hap1, Hap3, Hap5) have in common a number of repeats $n \geq 17$ (Alleles $M$ or $L$ ). This characteristic was also shared by Hap7, a less frequent haplotype in our study population (3\%). The sub-classification of the alleles of this polymorphic marker into three subclasses (Alleles $\mathrm{S}, \mathrm{M}$ and $\mathrm{L}$ ) has unveiled a probable functional impact since lower expression of TLR2 due to weaker promoter activity was reported in individuals with smaller repeat numbers (S allele) (Yim et al., 2004, 2006, 2008, Lee et al., 2006; Folwaczny et al., 2011).

The Hap7 haplotype ([Del]-T-[M or L]) was relevant to the infectious subphenotypes in SCA considered in this study. The deleterious effect of Hap7 was observed through a statistically significant increase in the incidence rate in severe bacterial infections in SCA, resisting the Bonferroni correction for multiple testing, with no influence of the covariables on the risk estimates. This haplotype presents both the -196 to -17422 bp deletion, localized in the TLR2 first untranslated exon, that was been associated with susceptibility to infections of various etiologies (Nischalke et al., 2011, 2012; Velez et al., 2010; Greene et al., 2012), and the SNP rs4696480 T allele, in the TLR2 promoter, associated in a preliminary study to susceptibility to pulmonary bacterial infections in sickle cell disease (Rostane et al., 2012). Relative to the (GT)n STR polymorphism in the TLR2 intron 2, it would appear to have a 
'normal' promoter activity. The observed effect of Hap7 was independent of statistically significant effects of the covariables.

501 The high statistical effects observed in our association studies were accompanied by wide confidence intervals. This lack of precision attests to the low number of cases in our study that could be resolved in future studies by contemplating a higher number of cases.

In earlier studies, TLR2 signaling was believed to have a role in mediating proinflammatory cytokines in a type I IFN independent inflammatory response rather than a specific type I 
523 toxicity of type I IFN alters innate and adaptive immune defenses against other 524 opportunistic infections including of bacterial origin (Trinchieri, 2010). As such, the protection against viral infections through this innate defense mechanism may increase the risk of bacterial opportunistic infections. Likewise, the genetic variants or haplotypes of the genetic determinants of the innate immune system that protect against one class of pathogens may be deleterious in relation to another. In our study however, the variants analyzed were in non coding regions and most likely implicated in transcriptional activity. The phenotype-to-genotype association results from our study indicated that these variants worked in the same manner relative to susceptibility/resistance whether the infections analyzed were of bacterial origin or primarily viral. Viral etiology was assigned to most of the respiratory infections in our study. In pediatric ages, viral infections are frequent and almost always benignant. However, from these results their frequency may be an indicator of susceptibility to more severe bacterial infections. It would be pertinent to evaluate the IFN responses in the presence of the TLR2variants and haplotypes in our study, for example in a human relevant cell/tissue ex vivo model. This result is particularly pertinent in the light of considerations on TLRs as a class of targets for therapies against infectious diseases (O'Neill et al., 2009).

The hemolytic component reflects direct markers of intravascular hemolysis in patients and allows for adjusted analysis of associations between hemolytic severity and clinical phenotypes (Nouraie et al., 2013). The levels of cell-free hemoglobin concentrations, a direct marker of hemolysis, not being available to us we worked with a hemolytic component derived by PCA from three proximal hemolytic markers namely steady state serum lactate dehydrogenase and total bilirubin, and reticulocyte count. A statistically significant association of the subphenotype "severe bacterial infections at least once during the patient's follow-up" was obtained with the hemolytic component, regardless of the 
patient TLR2genotype. An increase in the hemolytic component unit caused a decrease in the incidence rate of these infections. This is an unexpected observation. SCA is a hemolytic disease in which there is premature destruction of red blood cells. In a recent review Orf and Cunnington (2015) discussed how hemolysis, by liberating the heme moiety of hemoglobin and its iron, an essential element for both the host and the pathogen, induces pathophysiological changes that increase the risk of bacterial infection. The mechanisms by which this occurs are not fully understood and appear to differ amongst the different causes of hemolysis. However, these authors suggested that a general mechanism may be the impairment of neutrophil oxidative burst that has also been observed in sickle cell disease. The covariable effects as revealed in the quasipoisson regression model also need discussion. The covariables positively influencing this outcome were fetal hemoglobin levels (prior to hydroxyurea treatment) and 3.7-kb alphathalassemia. Fetal hemoglobin is a well known modulator of sickle cell disease severity, the protective effect being due to a higher oxygen binding capacity than that of adult hemoglobin A(Bridges et al., 1996). Alpha-thalassemia, another modulator reduces the formation of dense and irreversibly deoxyHbS sickled cells through the reduction in overall hemoglobin concentration, as a consequence of the absent alpha genes (Embury et al., 1984). Moreover, alpha-thalassemia has been associated with reduced hemolysis as measured by total steady state bilirubin and reticulocyte count (Coelho et al., 2014). Supporting the hemolytic component's relationship with the intensity of total hemolysis as previously reported (Driss et al., 2009), in our study the mean hemolytic component value was significantly lower with the 3.7-kb alpha-thalassemia genotypes. Moreover, a statistically significant negative association between the hemolytic component and steady state hemolglobin levels was observed. Therefore although hemolysis and 3.7-kb alphathalassemia are two factors generally working in opposition in SCA, in relation to the risk of 
573 infection they appear to contribute jointly towards its reduction. These results once more 574 denote the complex genetic architecture in the SCA hemolytic process.

575 In our study, the hemolytic component was shown to be an important modulator of severe 576 bacterial infection predisposition along with other more commonly investigated modulators 577 of SCA. Our results showed a positive influence of the covariables hemolytic component 578 and fetal hemoglobin levels (prior to hydroxyureia treatment)to the protective effect of the 579 TLR2 SNP c.-16934A>T allele A as well as the -196 to -174 indel Ins/Del genotype against 580 severe bacterial infection.

581 The hemolytic component had no TLR2 genotype independent effect on the advent of respiratory infections as a whole, which in our study are more frequently of viral origin. A statistical tendency that pointed to the deleterious effect of TLR2 SNP c.-16934A>T allele T 584 was observed, resulting in an increase in the incidence rate of respiratory infections. Contrary to what was observed with steady state hemoglobin levels, both covariables fetal hemoglobin levels (prior to hydroxyureia treatment) and 3.7-kb alpha-thalassemia acted to increase the incidence rate of these infections. The differences observed between the protective effects of 3.7-kb alpha-thalassemia against severe bacterial infection contrasts with its deleterious effect against respiratory infections where it appears to favor an increase in the incidence rate. Although this latter result is unexpected, negative epistasis between sickle hemoglobin and 3.7-kb alpha-thalassemia or between sickle hemoglobin and fetal hemoglobin levels resulting in an increased risk of malaria infection have been reported in epidemiologic studies in Kenya (Mmbando et al., 2015). 
596 This genotype-to-phenotype association study revealed important aspects relative to 597 statistical methodology and the pathophysiology of infection in pediatric SCA.

Methodologically, our study revealed the usefulness of time based cohorts in genotype-tophenotype association studies of infectious diseases at a time when whole genome crosssectional analysis is in vogue.

Our results evidenced the deleterious effect of the Hap7 haplotype ([Del]-T-[M or L]) in the incidence rate in severe bacterial infections in pediatric SCA. This haplotype presents both the -196 to -17422 bp deletion, localized in the TLR2 first untranslated exon, and the SNP rs4696480 T allele, in the TLR2 promoter, that have previously been associated with susceptibility to infections of various etiologies.

Another interesting aspect was the analysis of a hemolytic component. Hemolysis is a major pathophysiological feature of SCA. Our results show its relevance in relation to severe bacterial infections in a positive epistasis with $-\alpha^{37}$ thalassemia. An unexpected dichotomous relationship with- $\alpha^{37}$ thalassemia, suggested that a role in the protection against severe bacterial might favor recurrent viral infections, highlighting the complexity of the SCA hemolytic process in relation to infection.

These results should be further explored by replicating the findings in other cohorts to obtain definite conclusions; conducting prospective studies to prove the usefulness of $T L R 2$ information; applying detailed analysis of TLR2 loci to pick-up the most useful markers to be used in future clinical practice.

As we further and more deeply understand the genetic basis and the pathophysiological mechanisms involved, targeted and personalized interventions may come to reduce the morbidity and mortality attributable to infection in these particularly vulnerable SCA patients. 
621 The authors declare no conflict of interest.

\section{Acknowledgements}

624 We are grateful to the patients and their families. We also thank Dominique Labie for having 625 suggested this topic of research. We thank INSA's "Unidade de Tecnologia e Inovacão" as 626 well as Andreia Coelho and Emanuel Ferreira for technical support. We thank Eric David 627 Bosne for insight in PCA. We also thank Audrey V. Grant, Baltazar Nunes, Paula Faustino 628 and Vera C.M. David for their helpful suggestions in the elaboration of the study. This study was carried out with financial support from FCT/MEC through national funds and co-

630 financed by FEDER, under the Partnership Agreement PT2020, in the project with 631 reference UIDMULTI/00211/2013, and was partially funded by FCT grants

632 PIC/IC/83084/2007 and the Centro de Investigação em Genética Molecular Humana $633(\mathrm{CIGMH})$.

\section{Author contribution}

637 Conceived and designed the experiments: S David, A Dias, A Morais, J Lavinha.

638 Suggested methodologies: S David, A Dias, A Morais, A Sakuntabhai, J Lavinha.

639 Genotyped: S David. Reorganized the database: S David. Analyzed the data: S David, P 640 Aguiar. Carried out the investigation: S David. Provided the resources: A Dias, A Morais, J 
641 Lavinha. Wrote the paper: S David. Reviewed the paper: P Aguiar, J Lavinha, A

642 Sakuntabhai. All authors approved the final version of the paper.

644 Ethical approval: All procedures performed in studies involving human participants were in 645 accordance with the ethical standards of the institutional and/or national research 646 committee and with the 1964 Helsinki declaration and its later amendments or comparable 647 ethical standards.

Ahmed, SG (2011) The role of infection in the pathogenesis of vaso-occlusive crisis in patients with sickle cell disease. Mediterranean journal of hematology and infectious diseases 3(1): p.2011028

Alter, A, Grant, A, Abel, L, Alcaïs, A, Schurr, E (2011) Leprosy as a genetic disease. Mammalian genome 22(1-2): 19-31

Bagheri, V, Askari, A, Arababadi, MK, Kennedy, D (2014) Can Toll-Like Receptor (TLR) 2 be considered as a new target for immunotherapy against hepatitis B infection?. Human immunology 75(6): 549-554 
662 Barbalat, R, Lau, L, Locksley, RM, Barton, GM (2009) Toll-like receptor 2 on inflammatory monocytes induces type I interferon in response to viral but not bacterial ligands. Nature immunology 10(11): 1200-1207

Bland, JM, Altman, DG (1995) Multiple significance tests: the Bonferroni method. Bmj 310(6973): 170

Bottema, RW, Kerkhof, M, Reijmerink, NE, Thijs, C, Smit, HA, van Schayck, CP, Brunekreef, B, van Oosterhout, AJ, Postma, DS, Koppelman, GH (2010) Gene-gene interaction in regulatory $\mathrm{T}$-cell function in atopy and asthma development in childhood. Journal of Allergy and Clinical Immunology 126(2): 338-346

Bridges, KR, Barabino, GD, Brugnara, C, Cho, MR, Christoph, GW, Dover, G, Ewenstein, BM, Golan, DE, Guttmann, CR, Hofrichter, J, Mulkern, RV (1996) A multiparameter analysis of sickle erythrocytes in patients undergoing hydroxyurea therapy. Blood 88(12): 4701-4710

Cai, MS, Li, ML and Zheng, CF (2012) Herpesviral infection and Toll-like receptor 2. Protein \& cell 3(8): 590-601

Casanova, JL, Abel, L, Quintana-Murci, L (2011) Human TLRs and IL-1Rs in host defense: natural insights from evolutionary, epidemiological, and clinical genetics. Annual review of immunology 29: 447-491

Chen, J, Ng, MML, Chu, JJH (2015) Activation of TLR2 and TLR6 by dengue NS1 protein and its implications in the immunopathogenesis of dengue virus infection. PLoS Pathog 11(7): e1005053 
Chen, YC, Hsiao, CC, Chen, CJ, Chin, CH, Liu, SF, Wu, CC, Eng, HL, Chao, TY, Tsen, CC, Wang, YH, Lin, MC (2010) Toll-like receptor 2 gene polymorphisms, pulmonary tuberculosis, and natural killer cell counts. BMC medical genetics 11(1): 17

Coelho, A, Dias, A, Morais, A, Nunes, B, Ferreira, E, Picanço, I, Faustino, P, Lavinha, J (2014) Genetic variation in CD36, HBA, NOS3 and VCAM1 is associated with chronic haemolysis level in sickle cell anaemia: a longitudinal study. European journal of haematology, 92(3): 237-243

de Oliviera Nascimento, L, Massari, P, Wetzler, LM (2012) The role of TLR2 in infection and immunity. Frontiers in immunology, 3: 79

Driss, A, Asare, KO, Hibbert, JM, Gee, BE, Adamkiewicz, TV, Stiles, JK (2009) Sickle cell disease in the post genomic era: a monogenic disease with a polygenic phenotype. Genomics insights 2: 23

Eder, W, Klimecki, W, Yu, L, von Mutius, E, Riedler, J, Braun-Fahrländer, C, Nowak, D, Martinez, FD, ALEX Study Team (2004) Toll-like receptor 2 as a major gene for asthma in children of European farmers. Journal of allergy and clinical immunology 113(3): 482-488

Embury, SH, Clark, MR, Monroy, G, Mohandas, N (1984) Concurrent sickle cell anemia and alpha-thalassemia. Effect on pathological properties of sickle erythrocytes. Journal of Clinical Investigation, 73(1): 116

Esposito, S, Zampiero, A, Pugni, L, Tabano, S, Pelucchi, C, Ghirardi, B, Terranova, L, Miozzo, M, Mosca, F, Principi, N (2014) Genetic polymorphisms and sepsis in premature neonates. PloS one 9(7): e101248 
Folwaczny, M, Glas, J, Tonenchi, L, Török, HP (2011) Microsatellite GT polymorphism in intron 2 of human Toll-like receptor (TLR) 2 gene and susceptibility to periodontitis. Clinical oral investigations 15(3): 435-441

Greene, JA, Sam-Agudu, N, John, CC, Opoka, RO, Zimmerman, PA, Kazura, JW (2012) Toll-like receptor polymorphisms and cerebral malaria: TLR2 $\Delta 22$ polymorphism is associated with protection from cerebral malaria in a case control study. Malaria journal 11(1): 47.

Hawn, TR, Scholes, D, Li, SS, Wang, H, Yang, Y, Roberts, PL, Stapleton, AE, Janer, M, Aderem, A, Stamm, WE, Zhao, LP (2009) Toll-like receptor polymorphisms and susceptibility to urinary tract infections in adult women. PloS one 4(6): e5990

Hernandez, JC, Giraldo, DM, Paul, S, Urcuqui-Inchima, S (2015) Involvement of neutrophil hyporesponse and the role of Toll-like receptors in human immunodeficiency virus 1 protection. PloS one 10(3): e0119844

Hippenstiel, S, Opitz, B, Schmeck, B, Suttorp, N (2006) Lung epithelium as a sentinel and effector system in pneumonia-molecular mechanisms of pathogen recognition and signal transduction. Respiratory research 7(1): 97

Hishida, A, Matsuo, K, Goto, Y, Naito, M, Wakai, K, Tajima, K, Hamajima, N (2010) No associations of Toll-like receptor 2 (TLR2)-196 to-174del polymorphism with the risk of Helicobacter pylori seropositivity, gastric atrophy, and gastric cancer in Japanese. Gastric Cancer 13(4): 251-257

Ioana, M, Ferwerda, B, Plantinga, TS, Stappers, M, Oosting, M, McCall, M, Cimpoeru, A, Burada, F, Panduru, N, Sauerwein, R and Doumbo, O (2012) Different patterns of 
Toll-like receptor 2 polymorphisms in populations of various ethnic and geographic origins. Infection and immunity 80(5): 1917-1922

Kaul, DK, Fabry, ME, Nagel, RL (1996) The pathophysiology of vascular obstruction in the sickle syndromes. Blood reviews 10(1): 29-44

Kawai, T, Akira, S(2005) Pathogen recognition with Toll-like receptors. Current opinion in immunology 17(4): 338-344

Kawai, T, Akira, S(2011) Toll-like receptors and their crosstalk with other innate receptors in infection and immunity. Immunity 34(5): 637-650

Kerkhof, M, Postma, DS, Brunekreef, B, Reijmerink, NE, Wijga, AH, De Jongste, JC, Gehring, U, Koppelman, $\mathrm{GH}(2010)$ Toll-like receptor 2 and 4 genes influence susceptibility to adverse effects of traffic-related air pollution on childhood asthma. Thorax 65(8): 690-697

Klaassen, EM, Thönissen, BE, van Eys, G, Dompeling, E, Jöbsis, Q(2013) A systematic review of CD14 and toll-like receptors in relation to asthma in Caucasian children. Allergy, Asthma \& Clinical Immunology 9(1): 10

Kormann, MS, Depner, M, Hartl, D, Klopp, N, Illig, T, Adamski, J, Vogelberg, C, Weiland, SK, von Mutius, E, Kabesch, M(2008) Toll-like receptor heterodimer variants protect from childhood asthma. Journal of Allergy and Clinical Immunology 122(1): 86-92

Lee, EY, Yim, JJ, Lee, HS, Lee, YJ, Lee, EB, Song, YW(2006) Dinucleotide repeat polymorphism in intron II of human Toll-like receptor 2 gene and susceptibility to rheumatoid arthritis. International journal of immunogenetics 33(3): 211-215 
Lin, YT, Verma, A, P Hodgkinson, C(2012) Toll-like receptors and human disease: lessons from single nucleotide polymorphisms. Current genomics 13(8): 633-645

Liu, SY, Sanchez, DJ, Cheng, G(2011) New developments in the induction and antiviral effectors of type I interferon. Current opinion in immunology 23(1): 57-64

Ma, X, Liu, Y, Gowen, BB, Graviss, EA, Clark, AG, Musser, JM(2007) Full-exon resequencing reveals toll-like receptor variants contribute to human susceptibility to tuberculosis disease. PloS one 2(12): e1318

Ma, Y, He, B (2014) Recognition of herpes simplex viruses: toll-like receptors and beyond. Journal of molecular biology 426(6): 1133-1147

Medvedev, AE(2013) Toll-like receptor polymorphisms, inflammatory and infectious diseases, allergies, and cancer. Journal of Interferon \& Cytokine Research 33(9): 467484

Miedema, KGE, Tissing, WJE, Te Poele, EM, Kamps, WA, Alizadeh, BZ, Kerkhof, M, De Jongste, JC, Smit, HA, De Pagter, AP, Bierings, M, Boezen, HM(2012) Polymorphisms in the TLR6 gene associated with the inverse association between childhood acute lymphoblastic leukemia and atopic disease. Leukemia 26(6): 12031210

Misch, EA, Hawn, TR(2008) Toll-like receptor polymorphisms and susceptibility to human disease. Clinical Science 114(5): 347-360

Mmbando, BP, Mgaya, J, Cox, SE, Mtatiro, SN, Soka, D, Rwezaula, S, Meda, E, Msaki, E, Snow, RW, Jeffries, N, Geller, NL(2015) Negative Epistasis between sickle and foetal haemoglobin suggests a reduction in protection against malaria. PloS one 10(5): e0125929 
Mukherjee, S, Ganguli, D, Majumder, PP(2014) Global footprints of purifying selection on toll-like receptor genes primarily associated with response to bacterial infections in humans. Genome biology and evolution 6(3): 551-558

Nischalke, HD, Berger, C, Aldenhoff, K, Thyssen, L, Gentemann, M, Grünhage, F, Lammert, F, Nattermann, J, Sauerbruch, T, Spengler, U, Appenrodt, B(2011) Toll-like receptor (TLR) 2 promoter and intron 2 polymorphisms are associated with increased risk for spontaneous bacterial peritonitis in liver cirrhosis. Journal of hepatology 55(5): 1010-1016

Nischalke, HD, Coenen, M, Berger, C, Aldenhoff, K, Müller, T, Berg, T, Krämer, B, Körner, C, Odenthal, M, Schulze, F, Grünhage, F(2012) The toll-like receptor 2 (TLR2)-196 to-174 del/ins polymorphism affects viral loads and susceptibility to hepatocellular carcinoma in chronic hepatitis C. International journal of cancer 130(6): 1470-1475

Noguchi, E, Nishimura, F, Fukai, H, Kim, J, Ichikawa, K, Shibasaki, M, Arinami, T(2004) An association study of asthma and total serum immunoglobin E levels for Toll-like receptor polymorphisms in a Japanese population. Clinical \& Experimental Allergy 34(2): 177-183

Nouraie, M, Lee, JS, Zhang, Y, Kanias, T, Zhao, X, Xiong, Z, Oriss, TB, Zeng, Q, Kato, GJ, Gibbs, JSR, Hildesheim, ME(2013) The relationship between the severity of hemolysis, clinical manifestations and risk of death in 415 patients with sickle cell anemia in the US and Europe. Haematologica 98(3): 464-472

Novis, CL, Archin, NM, Buzon, MJ, Verdin, E, Round, JL, Lichterfeld, M, Margolis, DM, Planelles, V, Bosque, A(2013) Reactivation of latent HIV-1 in central memory CD4+ T cells through TLR-1/2 stimulation Retrovirology 10(1): 119 
O'Neill, LA, Bryant, CE, Doyle, SL(2009) Therapeutic targeting of Toll-like receptors for infectious and inflammatory diseases and cancer. Pharmacological reviews 61(2): $177-197$

Orf, K, Cunnington, $A(2015)$ Infection-related hemolysis and susceptibility to Gram-negative bacterial co-infection. Frontiers in microbiology 6: 666

Purcell, S, Neale, B, Todd-Brown, K, Thomas, L, Ferreira, MA, Bender, D, Maller, J, Sklar, P, De Bakker, PI, Daly, MJ, Sham, PC(2007) PLINK: a tool set for whole-genome association and population-based linkage analyses. The American Journal of Human Genetics 81(3): 559-575

Reuven, EM, Ali, M, Rotem, E, Schwarzter, R, Gramatica, A, Futerman, AH, Shai, Y(2014) The HIV-1 envelope transmembrane domain binds TLR2 through a distinct dimerization motif and inhibits TLR2-mediated responses. PLoS Pathog 10(8): e1004248

Rostane, H, Busson, M, Diallo, D(2012) Le risque d'infections bactériennes sévères au cours de la maladie drépanocytaire est influencé par un polymorphisme du promoteur du gène TLR-2. Congrès Soc Franc Hématol 2012; Globule rouge et fer\# 138. Hématologie 18(suppl 1): 26

Song, Z, Yin, J, Yao, C, Sun, Z, Shao, M, Zhang, Y, Tao, Z, Huang, P, Tong, C(2011) Variants in the Toll-interacting protein gene are associated with susceptibility to sepsis in the Chinese Han population. Critical care 15(1): R12

Steinberg, $\mathrm{MH}$, Embury, $\mathrm{SH}(1986)$ Alpha-thalassemia in blacks: genetic and clinical aspects and interactions with the sickle hemoglobin gene. Blood 68(5): 985-990 
816 Steinberg, MH, Sebastiani, P(2012) Genetic modifiers of sickle cell disease. American journal of hematology 87(8): 795-803

Steinberg, $\mathrm{MH}(2008)$ Sickle cell anemia, the first molecular disease: overview of molecular etiology, pathophysiology, and therapeutic approaches. The Scientific World Journal 8: $1295-1324$

Stephens, M, Donnelly, P(2003) A comparison of bayesian methods for haplotype reconstruction from population genotype data. The American Journal of Human Genetics 73(5): 1162-1169

Stephens, M, Smith, NJ, Donnelly, P(2001) A new statistical method for haplotype reconstruction from population data. The American Journal of Human Genetics 68(4): 978-989

Tahara, T, Arisawa, T, Wang, F, Shibata, T, Nakamura, M, Sakata, M, Hirata, I, Nakano, H (2007) Toll-like receptor 2-196 to 174del polymorphism influences the susceptibility of Japanese people to gastric cancer. Cancer science 98(11): 1790-1794

Takeda, K, Kaisho, T, Akira, S(2003) Toll-like receptors. Annual review of immunology 21(1): $335-376$

Takeuchi, O, Akira, S(2010) Pattern recognition receptors and inflammation. Cell 140(6): $805-820$

Team, RC(2013) Vienna, Austria: R Foundation for Statistical Computing; 2013. R: A language and environment for statistical computing

Thompson, JM, Iwasaki, A(2008) Toll-like receptors regulation of viral infection and disease. Advanced drug delivery reviews 60(7): 786-794 
Triantafilou, K, Eryilmazlar, D, Triantafilou, M(2014) Herpes simplex virus 2-induced activation in vaginal cells involves Toll-like receptors 2 and 9 and DNA sensors DAI and IFI16. American journal of obstetrics and gynecology 210(2): 122-e1

Trinchieri, G(2010) Type I interferon: friend or foe?. Journal of Experimental Medicinejem20101664

Velez, DR, Wejse, C, Stryjewski, ME, Abbate, E, Hulme, WF, Myers, JL, Estevan, R, Patillo, SG, Olesen, R, Tacconelli, A, Sirugo, G(2010) Variants in toll-like receptors 2 and 9 influence susceptibility to pulmonary tuberculosis in Caucasians, AfricanAmericans, and West Africans. Human genetics 127(1): 65-73

Ver Hoef, JM, Boveng, PL(2007) Quasi-Poisson vs. negative binomial regression: how should we model overdispersed count data?. Ecology 88(11): 2766-2772

Wu, Q, Chu, HW(2009) Role of infections in the induction and development of asthma: genetic and inflammatory drivers. Expert review of clinical immunology 5(1): 97-109

Yim, JJ, Ding, L, Schäffer, AA, Park, GY, Shim, YS, Holland, SM(2004) A microsatellite polymorphism in intron 2 of human Toll-like receptor 2 gene: functional implications and racial differences. FEMS Immunology \& Medical Microbiology 40(2): 163-169

Yim, JJ, Kim, HJ, Kwon, OJ, Koh, WJ(2008) Association between microsatellite polymorphisms in intron II of the human Toll-like receptor 2 gene and nontuberculous mycobacterial lung disease in a Korean population. Human immunology 69(9): 572576

Yim, JJ, Lee, HW, Lee, HS, Kim, YW, Han, SK, Shim, YS, Holland, SM(2006) The association between microsatellite polymorphisms in intron II of the human Toll-like receptor 2 gene and tuberculosis among Koreans. Genes and immunity 7(2): 150-155 
861 Zeng, HM, Pan, KF, Zhang, Y, Zhang, L, Ma, JL, Zhou, T, Su, HJ, Li, WQ, Li, JY, Gerhard, 862 M, Classen, M(2011) Genetic variants of toll-like receptor 2 and 5, helicobacter pylori 863 infection, and risk of gastric cancer and its precursors in a chinese population. Cancer $864 \quad$ Epidemiology and Prevention Biomarkers 20(12): 2594-602

865 Zhang, Y, Jiang, T, Yang, X, Xue, Y, Wang, C, Liu, J, Zhang, X, Chen, Z, Zhao, M, Li, 866 JC(2013) Toll-like receptor-1,-2, and-6 polymorphisms and pulmonary tuberculosis susceptibility: a systematic review and meta-analysis. PloS one 8(5): e63357 
Table 1

870 Haplotype distribution of the three TLR2 loci observed in the SCA pediatric patients $(\mathrm{n}=95)$

\begin{tabular}{lllll}
\hline Name & \multicolumn{2}{c}{ Haplotype $^{1}$ (two notations) } & Frequency & S.E \\
\hline Hap1 & 101 & [Ins]-A-[M or L] & 0,174 & 0,011 \\
Hap2 & 100 & [Ins]-A-[S] & 0,028 & 0,006 \\
Hap3 & 111 & [Ins]-T-[M or L] & 0,491 & 0,013 \\
Hap4 & 110 & [Ins]-T-[S] & 0,048 & 0,010 \\
Hap5 & 001 & [Del]-A-[M or L] & 0,182 & 0,012 \\
Hap6 & 000 & [Del]-A-[S] & 0,039 & 0,008 \\
Hap7 & 011 & [Del]-T-[M or L] & 0,030 & 0,001 \\
Hap8 & 010 & [Del]-T-[S] & 0,008 & 0,007 \\
\hline
\end{tabular}

${ }^{1}$ Haplotypes were defined for all three loci detected in the TLR2 using the PHASE, version

2.1, program $[64,65]$. Relative to the arbitrary position c.-18619, the genetic distance in bp of the three loci was $5^{\prime}--196$ to -17422 bp nucleotide indel (untranslated exon 1) - SNP rs4696480, c.-16934A>T (promoter) - the (GT)n STR polymorphism (intron 2) - 3':

66/1685/18475 bp respectively. Using the PHASE program eight haplotypes were identified: Hap1, 101 ([Ins]-A-[M or L]); Hap2, 100 ([Ins]-A-[S]); Hap3, 111 ([Ins]-T-[M or L]); Hap4, 110 ([Ins]-T-[S]); Hap5, 001 ([Del]-A-[M or L]); Hap6, 000 ([Del]-A-[S]); Hap7, 011 ([Del]-T-[M or L]); Hap8, 010 ([Del]-T-[S]). For the TLR2 STR, the following subdivision based on the number of repeats $(n)$ was used: Allele $S, n \leq 16$; Allele $M, 17 \leq n \leq 22$, and Allele $L, n \geq 23$, which was further simplified as a binary variable $S$ versus others ( $M$ or $L$ )

881 (Yim et al., 2006).

${ }^{2}$ Haplotype frequency from the present study

883 Note: For the indel: 1 (Ins) = insertion; 0 (Del) = deletion; for the SNP: $1=$ T allele (major); 0 $884=$ A allele (minor); for the microsatellite (STR): $0=\mathrm{S}$ allele $[(\mathrm{GT}) \leq 16], 1=\mathrm{M}$ or $\mathrm{L}$ alleles $([17$ 885 $\leq(\mathrm{GT}) \leq 22]$ and $[(\mathrm{GT}) \geq 23]$, respectively) 
886 Abbreviations: SCA, sickle cell anemia; S.E., standard error; SNP, single nucleotide 887 polymorphism; Hap, haplotype; Indel, insertion or deletion variation. 
890 Results of the preliminary genotype-to-phenotype association study of TLR2 SNP

891 rs4696480 in SCA pediatric patients $(n=95)$

\begin{tabular}{cll}
\hline Phenotype $^{1}$ & TEST $^{2}$ & p-value \\
\hline A & ALLELIC & 0.007167 \\
A & TREND & 0.009488 \\
A & ADD & 0.01152 \\
B & ALLELIC & 0.1805 \\
B & TREND & 0.1964 \\
B & ADD & 0.2056 \\
C & ALLELIC & 0.2226 \\
C & TREND & 0.2393 \\
C & ADD & 0.2416 \\
D & ALLELIC & 0.3874 \\
D & TREND & 0.4044 \\
D & ADD & 0.4056 \\
E & REC & 0.6686 \\
F & ALLELIC & 0.7261 \\
F & TREND & 0.7355 \\
F & ADD & 0.7356 \\
E & ALLELIC & 0.762 \\
E & TREND & 0.7702 \\
E & ADD & 0.7703 \\
E & GEN & 0.9098 \\
E & DOM & 0.9321 \\
\hline
\end{tabular}

$892{ }^{1}$ Infectious phenotype: (A) "number of respiratory infections during the patient's follow-up"; 893 (B) "severe bacterial infections at least once during the patient's follow-up"; (C) "number of 894 all infectious episodes during the patient's follow-up"; (D) "number of infectious episodes 895 without hospitalization during the patient's follow-up"; (E) "number of infectious episodes 896 with hospitalization during the patient's follow-up"; (F) "number of infections other than 897 respiratory during the patient's follow-up". For the analysis the quantitative variables were 898 transformed into binary traits; a positive relationship was obtained when "the average rates 899 of the phenotype per patient (number of infections/ time at risk)/ the average rates of the 
900 phenotype for all the patients (number of infections/ time at risk) $(n=95)$ " $>1$. The only 901 originally binary trait was (B).

$902{ }^{2}$ Using the open-source whole genome association analysis toolset PLINK v1.07 program 903 (Purcell et al., 2007), six association tests were carried out for the SNP in analysis: the 904 Cochran-Armitage trend test (TREND) and five genotypic tests including the Additive test, 905 measuring additive effects of allele dosage (ADD), Genotypic (2 df) test (GEN), Allelic test 906 (ALLELIC),Dominant gene action (1df) test (DOM), Recessive gene action (1df) test (REC). 907 Only those results for which the chi-squared test was applicable are shown.

908 Abbreviations: SCA, sickle cell anemia. 


\section{Table 3}

Quasi-poisson regression analysis ${ }^{1}$ for the phenotype $(A)$ "number of respiratory infections during the patient's follow-up", in SCA pediatric patients $(n=95)$ relative to $T L R 2$ variants for rs 4696480

\begin{tabular}{|c|c|c|c|c|c|c|c|}
\hline Estimate & S.E. & $Z$ value & $p$-value ${ }^{4}$ & $\begin{array}{l}\text { Incidence } \\
\text { rate ratio }\end{array}$ & $\begin{array}{c}\text { Cl } \\
\text { Lower Limit }\end{array}$ & $\begin{array}{c}\text { Cl } \\
\text { Upper Limit }\end{array}$ & $\begin{array}{l}\text { Incidence rate ratio } \\
\text { reduction/increase (\%) }\end{array}$ \\
\hline
\end{tabular}

\section{Allelic model}

$\mathrm{T}$

Fetal hemoglobin ${ }^{2}$

$2.98 \quad 1.06$

2.80

$\begin{array}{llll}0.00903 * * & 19.6128131 & 2.452477460 & 156.8464717 \\ 0.02451 * & 1.1146879 & 1.019245354 & 1.2190677 \\ 0.00321 * * & 3.6534094 & 1.661834046 & 8.0317288 \\ 0.03169 * & 0.5200436 & 0.295078447 & 0.9165201\end{array}$

1861

0.11

0.05

2.38

$\begin{array}{lll}-2.84 & 1.07 & -2.65 \\ 0.11 & 0.05 & 2.43 \\ 1.40 & 0.42 & 3.38 \\ -0.68 & 0.28 & -2.39\end{array}$

$\begin{array}{llll}0.01328 * & 0.05815951 & 0.0070963 & 0.4766610 \\ 0.02226 * & 1.11546060 & 1.0211839 & 1.2184410 \\ 0.00224 * * & 4.07171727 & 1.8024320 & 9.1980620 \\ 0.02392 * & 0.50816920 & 0.2919040 & 0.8846606\end{array}$

A/A

Fetal hemoglobin ${ }^{2}$

$-0.68$

0.28

$-2.39$

0.02392 * $0.50816920 \quad 0.2919040$

Steady state hemoglobin ${ }^{3}$

(2)

\footnotetext{
${ }^{1}$ Statistical model: generalized linear model,Phenotype $\sim$ Genotype + steady state hemoglobin level + steady state leukocyte count + fetal hemoglobin (prior to hydroxyurea treatment) + haemolytic component + alpha-thalassemia. The Phenotype = "number of respiratory infections during the patient's follow-up".
} 
The reference group for the allelic model was allele A. The reference group for $-\alpha^{3}$ thalessemia was the absence of $-\alpha^{3}$ thalassemia. For the fetal hemoglobin there was no reference group. For steady state hemoglobin there was no reference group.

${ }^{2}$ Fetal hemoglobin (\%).

${ }^{3}$ Steady state hemoglobin $(\mathrm{g} / \mathrm{dL})$.

${ }^{4}$ The Bonferroni adjusted $\alpha=0.001667$, where the number of tests performed per inheritance model per locus $\mathrm{n}=30$.

Note 1: The interactions between factors were tested but because they were not statistically significant they were not included in the final model.

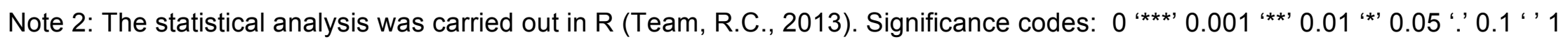

Abreviations: SCA, sickle cell anemia; S.E., Standard Error; CI, Confidence interval. 


\section{Table 4}

Significant results of the quasi-poisson regression analysis ${ }^{1}$ for the phenotype (B) "severe bacterial infections at least once during the patient's follow-up", in SCA pediatric patients $(n=95)$ relative to $T L R 2$ variants for $r 4696480$

\begin{tabular}{|c|c|c|c|c|c|c|c|}
\hline Estimate & S.E. & $Z$ value & $p$-value ${ }^{5}$ & $\begin{array}{l}\text { Incidence rate } \\
\text { ratio }\end{array}$ & $\begin{array}{c}\mathrm{Cl} \\
\text { Lower Limit }\end{array}$ & $\begin{array}{c}\mathrm{Cl} \\
\text { Upper Limit }\end{array}$ & $\begin{array}{l}\text { Incidence rate ratio } \\
\text { reduction/increase }(\%\end{array}$ \\
\hline
\end{tabular}

\section{Genotypic model}

$\mathrm{A} / \mathrm{T}$

$\begin{array}{lllllll}2.7173 & 0.8397 & 3.236 & 0.00311^{* *} & 1.513988 \mathrm{e}+01 & 2.920059 \mathrm{e}+00 & 78.49705859 \\ -1.4491 & 0.4238 & -3.420 & 0.00194^{* *} & 2.347796 \mathrm{e}-01 & 1.023152 \mathrm{e}-01 & 0.53874169 \\ -0.7724 & 0.2350 & -3.287 & 0.00273^{* *} & 4.619032 \mathrm{e}-01 & 2.914266 \mathrm{e}-01 & 0.73210412 \\ 0.5257 & 0.1545 & 3.404 & 0.00202^{* *} & 1.691717 \mathrm{e}+00 & 1.249840 \mathrm{e}+00 & 2.28981750\end{array}$

1413

$-77$

$-54$

69

\footnotetext{
${ }^{1}$ Statistical model: generalized linear model, Phenotype Genotype + steady state hemoglobin level + steady state leukocyte count + fetal hemoglobin (prior to hydroxyurea treatment) + haemolytic component + alpha-thalassemia. The Phenotype = "respiratory infections during the patient's follow-up". The reference group for the allelic model was T. For the hemolytic component there was no reference group. For the fetal hemoglobin there was no reference group. The reference group for $-\alpha^{37}$ thalessemia was the absence of $-\alpha^{37}$ thalassemia. The reference group for the $H B B^{*} S$ haplotype [Bantu/Bantu] was [Other than Bantu]/ [Other than Bantu]. For the steady state leukocyte count there was no reference group.

${ }^{2}$ Hemolytic component per score unit.

${ }^{3}$ Fetal hemoglobin (\%).
} 
${ }^{4}$ Steady state leukocyte count $\left(10^{9} / \mathrm{L}\right)$

${ }^{5}$ The Bonferroni adjusted $\alpha=0.001471$, where the number of tests performed per inheritance model per locus $\mathrm{n}=34$.

Note 1: The interactions between factors were tested but because they were not statistically significant they were not included in the final model.

Note 2: The statistical analysis was carried out in R (Team, R.C., 2013). Significance codes: 0 ‘*** 0.001 ‘**’ 0.01 ‘*’ 0.05 ' 0.1 ' ’ 1

Abreviations: SCA, sickle cell anemia; S.E., Standard Error; Cl, Confidence interval. 
Table 5

Significant results of the quasi-poisson regression analysis ${ }^{1}$ for the phenotype "severe bacterial infections at least once during the patient's follow-up", in SCA pediatric patients $(n=95)$ relative to $T L R 2$ variants for the -196 to 174 indel

\begin{tabular}{|c|c|c|c|c|c|c|c|}
\hline Estimate & S.E & $Z$ value & $p$-value ${ }^{4}$ & $\begin{array}{l}\text { Incidence rate } \\
\text { ratio }\end{array}$ & $\begin{array}{c}\mathrm{Cl} \\
\text { Lower Limit }\end{array}$ & $\begin{array}{c}\mathrm{Cl} \\
\text { Upper Limit }\end{array}$ & $\begin{array}{l}\text { Incidence rate ratio } \\
\text { reduction/increase (\%) }\end{array}$ \\
\hline
\end{tabular}

\section{Allelic model}

Ins

$\begin{array}{lllllll}-1.7843 & 0.7897 & -2.260 & 0.0308^{*} & 0.1679149 & 0.03572185 & 0.7893046 \\ -0.7306 & 0.3117 & -2.344 & 0.0255^{*} & 0.4816236 & 0.26144550 & 0.8872261 \\ -0.4591 & 0.1989 & -2.307 & 0.0277^{*} & 0.6318783 & 0.42784553 & 0.9332111\end{array}$

$-83$

Hemolytic component ${ }^{2}$

Fetal hemoglobin ${ }^{3}$

$-0.4591$

$\begin{array}{lll}1.9527 & 0.8972 & 2.176 \\ -1.2606 & 0.4914 & -2.566 \\ -0.5551 & 0.2365 & -2.347\end{array}$

$0.0381 *$

7.04802251

$1.2143868794 \quad 40.9051038$

605

Del/Del

$-0.5551$

0.0262 *

0.28347897

$0.1082098581 \quad 0.7426341$

$-72$

Fetal hemoglobin ${ }^{3}$

$0.0262 * 0.57402478$

$0.3610729097 \quad 0.9125704$

$-43$

\footnotetext{
${ }^{1}$ Statistical model: generalized linear model, Phenotype $\sim$ Genotype + steady state hemoglobin level + steady state leukocyte count + fetal hemoglobin $($ prior to hydroxyurea treatment) + haemolytic component + alpha-thalassemia. The Phenotype = "severe bacterial infections at least once during the patient's follow-up". The reference group for the genotypic model was Ins/Ins. For the hemolytic component there was no reference group. For the fetal hemoglobin
} 
there was no reference group. The reference group for $-\alpha^{3 / 7}$ thalessemia was the absence of $-\alpha^{3}$ thalassemia. The reference group for the $H B B^{*} S$ haplotype [Bantu/Bantu] was [Other than Bantu]/ [Other than Bantu]. The reference group for male gender was female gender.

${ }^{2}$ Hemolytic component per score unit.

${ }^{3}$ Fetal hemoglobin (\%).

${ }^{4}$ The Bonferroni adjusted $\alpha=0.001471$, where the number of tests performed per inheritance model per locus $\mathrm{n}=34$.

Note 1: The interactions between factors were tested but because they were not statistically significant they were not included in the final model.

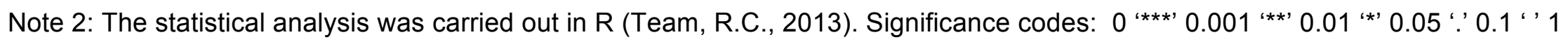

Abreviations: SCA, sickle cell anemia; S.E., Standard Error; CI, Confidence interval; Indel, insertion or deletion variation; Del, deletion; Ins, insertion. 


\section{Table 6}

Quasi-poisson regression model ${ }^{1}$ for the phenotype "severe bacterial infections at least once during the patient's follow-up" in SCA pediatric patients $(\mathrm{n}=95)$ relative to $T L R 2$ haplotype 7

\begin{tabular}{|c|c|c|c|c|c|c|c|}
\hline Estimate & S.E. & $Z$ value & $p$-value ${ }^{2}$ & $\begin{array}{l}\text { Incidence } \\
\text { rate ratio }\end{array}$ & $\begin{array}{c}\mathrm{Cl} \\
\text { Lower Limit }\end{array}$ & $\begin{array}{c}\mathrm{Cl} \\
\text { Upper Limit }\end{array}$ & $\begin{array}{l}\text { Incidence rate ratio } \\
\text { reduction/increase (\%) }\end{array}$ \\
\hline
\end{tabular}

\section{Allelic model}

Hap7

Genotypic model

[Other than Hap7]/[Other than Hap7] $\quad-2.52$

$\begin{array}{llllll}0.75 & -3.37 & 0.00145 * * & 0.08086037 & 0.01874114 & 0.3488796\end{array}$

$-92$

\footnotetext{
${ }^{1}$ Statistical model: quasipoisson regression modelin a generalized linear model,Phenotype $\sim$ Genotype + steady state hemoglobin level + steady state leukocyte count + fetal hemoglobin (prior to hydroxyurea treatment) + haemolytic component + alpha-thalassemia. The Phenotype $=$ "severe bacterial infections at least once during the patient's follow-up". The reference group for the allelic model was the absence of Hap7 ([Other than Hap7]). The reference group for the genotypic modelwas Hap7/Hap7.
}

${ }^{2}$ The Bonferroni adjusted $\alpha=0.001471$, where the number of tests performed per inheritance model per locus $\mathrm{n}=34$.

Note 1:The interactions between factors were tested but because they were not statistically significant they were not included in the final model.

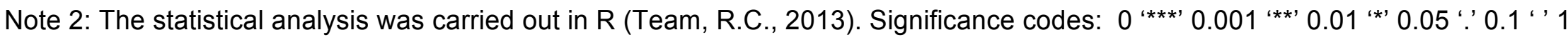


Abbreviations: SCA, sickle cell anemia; S.E., standard error; Hap, haplotype; Cl, Confidence interval. 
Table 7

Quasi-poisson regression model ${ }^{1}$ for the infectious phenotype "severe bacterial infections at least once during the patient's follow-up" in SCA pediatric patients ( $n=95)$ relative to the hemolytic component

\begin{tabular}{|c|c|c|c|c|c|c|c|}
\hline Estimate & S.E. & $Z$ value & $p$-value & $\begin{array}{l}\text { Incidence rate } \\
\text { ratio }\end{array}$ & $\begin{array}{c}\mathrm{Cl} \\
\text { Lower Limit }\end{array}$ & $\begin{array}{c}\mathrm{Cl} \\
\text { Upper Limit }\end{array}$ & $\begin{array}{l}\text { Incidence rate } \\
\text { ratioreduction/increase } \\
(\%)\end{array}$ \\
\hline
\end{tabular}

$\begin{array}{llllllllr}\text { Hemolytic component }^{2} & -1.7206 & 0.4285 & -4.015 & 0.000366 * * * & 0.17896141 & 0.077266233 & 4.145043 \mathrm{e}-01 & -82 \\ \text { Fetal hemoglobin }^{3} & -0.7612 & 0.2457 & -3.098 & 0.004205^{* *} & 0.46708616 & 0.288567509 & 7.560431 \mathrm{e}-01 & -53 \\ -\alpha^{3:} \text { thalassemia alleles } & -2.6593 & 1.1501 & -2.312 & 0.027811^{*} & 0.07000001 & 0.007347522 & 6.668916 \mathrm{e}-01\end{array}$

\footnotetext{
${ }^{1}$ Statistical model: quasipoisson regression modelin a generalized linear model,Phenotype $\sim$ Genotype + steady state hemoglobin level + steady state leukocyte count + fetal hemoglobin (prior to hydroxyurea treatment) + haemolytic component + alpha-thalassemia. The Phenotype = "severe bacterial infections at least once during the patient's follow-up". For the hemolytic component there was no reference group. For the fetal hemoglobin there was no reference group. The reference group for $-\alpha^{37}$ thalessemia was the absence of $-\alpha^{37}$ thalassemia. The reference group for the $H B B^{*} S$ haplotype [Bantu/Bantu] was [Other than Bantu]/ [Other than Bantu].

${ }^{2}$ Hemolytic component per score unit

${ }^{3}$ Fetal hemoglobin (\%).
}

Note 1:The interactions between factors were tested but because they were not statistically significant they were not included in the final model. 
Note 2: The statistical analysis was carried out in R (Team, R.C., 2013). Significance codes: 0 ‘**” 0.001 '**’ 0.01 ‘*’ 0.05 '? 0.1 “' 1

Abbreviations: SCA, sickle cell anemia; S.E., standard error; $\mathrm{Cl}$, Confidence interval. 


\section{Legends to Figures}

Fig. 1.Age distribution curve of the study cohort consisting of a total of 99 unrelated pediatric patients with SCA enrolled in a previous longitudinal study (Coelho et al., 2014). A sub-group of 95 patients was selected for the genotype-to-phenotype association studies based on the criterion of infectious episodes occurring within a range of over three and under 20 years of age. In the figure, the cutoff is illustrated by a vertical grey line. The total observation period for the cohort was 433.4 person*years, the average age at observation was $7.7 \pm 3.7$ years and the mean follow-up per patient was $4.6 \pm 1.5$ years. The M/F sex ratio was 1.21. Each bar represents one patient.

Fig. 2. Classification of observational periods as either infectious episodes, episodes without infection or episodes without reference to infection, within vasoocclusive crisis (VOC) and between crises (steady-state) (IC). Infectious disease phenotypes were reported for the SCA pediatric patients $(n=95)$ where the infectious episodes occurred within a range of over three and under 20 years of age.

Fig. 3. Phenotypic characterization of the infectious episodes according to the etiological agent for: $(A)$ all the infectious episodes $(n=527)$; $(B)$ episodes of respiratory infections ( $n$ = 102). The infectious status of the patients during the follow-up was determined by standard procedures and collected from the patients' hospital records. The $10^{\text {th }}$ revision of the International Statistical Classification of Diseases and Related Health Problems (ICD10) http://apps.who.int/classifications/icd10/browse/2016/en, was used to classify the infectious episodes. 
Figure 1

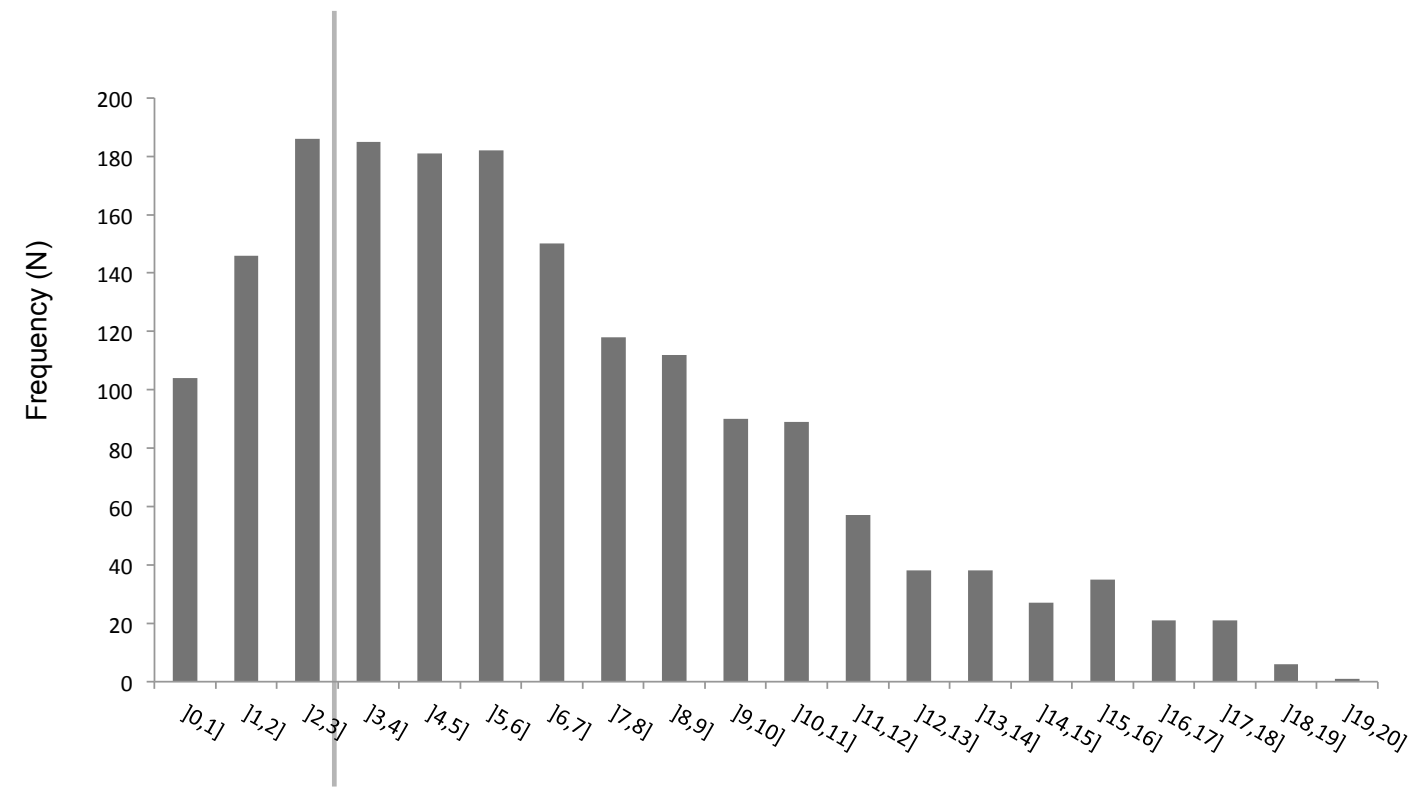

Age groups (years) 
Figure 2

vasooclusive crisis $(n=484) \quad$ intercrisis $(n=867)$
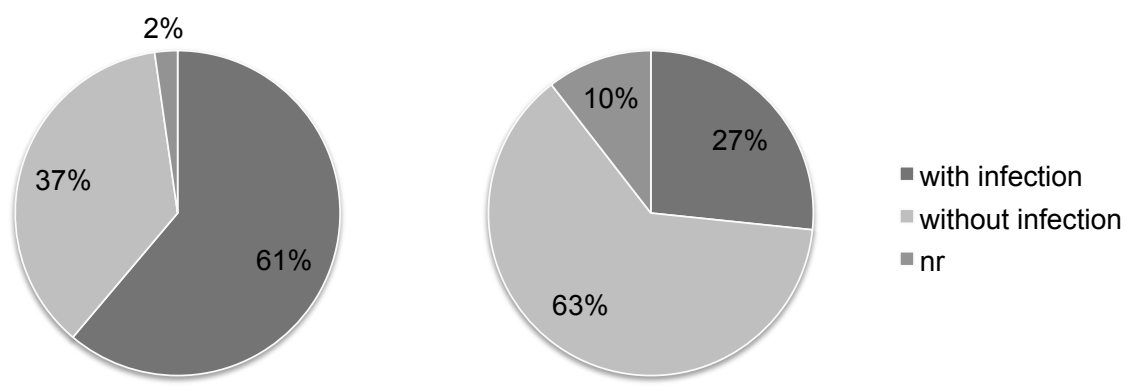
Figure 3

A

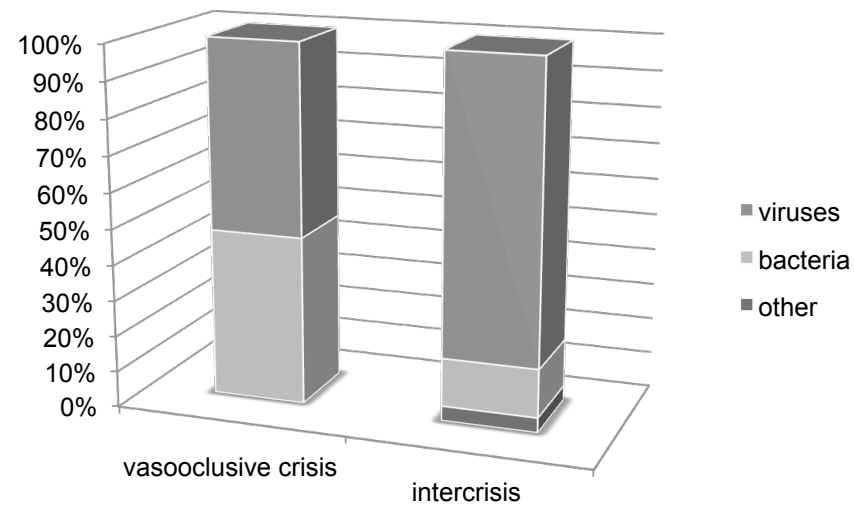

B

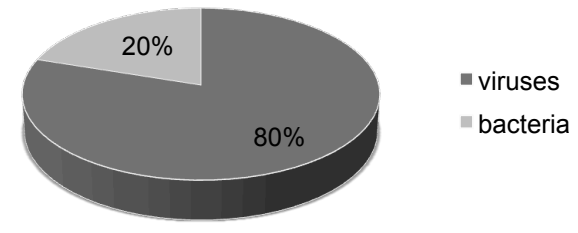

